\title{
Addressing the Issue of Food Insecurity on College Campuses
}

Linda L. Thompson PhD, LN

Department of Nutritional Sciences, Howard University, Washington, DC

Mateja R. Savoie-Roskos PhD, MPH, RDN

Department of Nutrition, Dietetics, and Food Sciences, Utah State University, Logan, UT

Email: mateja.savoie@usu.edu

Alisha R. Farris, PhD, RDN

Department of Nutrition and Health Care Management, Appalachian State University, Boone, NC

Kristin Riggsbee

Department of Nutrition, University of Tennessee, Knoxville, TN

Sa'Nealdra Wiggins

Department of Nutrition, University of Tennessee, Knoxville, TN

Food insecurity among college students is becoming a more widely recognized issue across the country. Recent studies report between $30-50 \%$ of college students experience some level of food insecurity, a rate that is nearly two-fold higher than the general public. 1,2,3 Although food insecurity has likely existed among this population for many years, it has recently become more intensely studied potentially due to the changing demographic characteristics of the average student. ${ }^{1}$ More than ever before, students are single parents, full-time employees, and/or first generation college students. ${ }^{1,2}$ These non-traditional students often experience financial obligations that can impact their ability to access an adequate amount of nutritious food for themselves and their families. ${ }^{2}$ This is especially concerning considering food insecurity among college students has been associated with overall poor health, poor eating behaviors, and adverse academic outcomes. ${ }^{1}$

Demographic groups who are at a higher risk for food insecurity among the general population are also more likely to experience food insecurity as students. ${ }^{1}$ While a study at a prominent historically black college/university (HBCU) reported nearly $78 \%$ of students surveyed had experienced some level of food insecurity over the prior 12 months, ${ }^{4}$ more research is needed on student populations from HBCU, rural/small town settings, Hispanic institutions, community and technical colleges, and for-profit universities.1,5,6

Some academic institutions across the country have been internally addressing campus food insecurity by providing access to food pantries, meal swipe programs, and food scholarships to students. ${ }^{2}$ Referring eligible students to the Supplemental Nutrition Assistance Program (SNAP) is another strategy to improve food security. ${ }^{2}$ Nearly 2 million students in 2016 were SNAP-eligible but did not apply or receive benefits. ${ }^{2}$ Furthermore, 
only one-third of state agencies reported actively informing college students about SNAP eligibility. ${ }^{2}$ Further research should assess how effective these interventions are at reducing the prevalence of food insecurity among this population. ${ }^{6}$

Nutrition professionals who are affiliated with colleges and universities across the country have the potential to lead efforts to improve food security status of college students by 1) raising awareness among students, faculty, and administrators about the extent to which food insecurity exists on their campus, 2) advocating for on-campus initiatives to improve access to and availability of food and nutrition assistance benefits for students, and 3) conducting research to determine long-term solutions to reducing food insecurity among this population.

References

1. Bruening M, Woerden IV, Todd M, Laska MN. Hungry to learn: The prevalence and effects of food insecurity on health behaviors and outcomes over time among a diverse sample of university freshmen. Int J Behav Nutr Phys Act. 2018;15(1). doi:10.1186/s12966-018-0647-7.

2. United States Government Accountability Office. Food insecurity: Better information could help eligible college students access federal food assistance benefits. https://www.gao.gov/products/GA0-19-95. Published January 9, 2019. Accessed February 21, 2019.

3. Knol LL, Robb CA, McKinley EM, Wood M. Very low food security status is related to lower cooking self-efficacy and less frequent food preparation behaviors among college students. [published online ahead of print December 8, 2018]. J Nutr Educ Behav. https://doi.org/10.1016/j.jneb.2018.10.009.

4. Thompson LL, Gayle LNR, Castor, C. College student food insecurity and its relationship to fruit and vegetable intake and overweight/obesity at a HBCU. J Nutr Health Food Eng. 2018;8(3),275-278. doi: 10.15406/jnhfe.2018.08.00282

5. Morris LM, Smith S, Davis J, Boyd Null D. The prevalence of food security and insecurity among Illinois university students. J Nutr Educ Behav. 2016;48(6), 376382. doi.org/10.1016/j.jneb.2016.03.013

6. McArthur LH, Ball L, Danek A, Holbert D. A high prevalence of food insecurity among university students in Appalachia reflects a need for educational interventions and policy advocacy. J Nutr Educ Behav. 2018;50(6):564-572. doi.org/10.1016/j.jneb. 2017.10.011 